УДК 930.2

\title{
«СУБЪЕКТИВНЫЙ МЕТОД» Н.К. МИХАЙЛОВСКОГО В СОЦИОЛОГИИ И ИСТОРИИ: ПРЕДПОСЫЛОЧНОЕ ЗНАНИЕ, СОПЕРЕЖИВАНИЕ, НРАВСТВЕННАЯ ОЦЕНКА
}

\author{
(c) 2020 О.Б. Леонтьева
}

Самарский национальный исследовательский университет имени академика С.П. Королева

Статья поступила в редакцию 11.11.2020

\begin{abstract}
В статье рассматриваются основы теоретико-методологического подхода к изучению человеческого общества, который предложил в конце XIX в. ведущий идеолог народничества Н.К. Михайловский. Сопоставляются перспективы применения «субъективного метода», разработанного Михайловским, в социологии и в исторической науке. Выделено несколько составляющих субъективного метода в трактовке Михайловского: «предвзятое мнение» (предпосылочное знание), сопереживание объекту изучения, реконструкция идеалов и целей людей прошлого, их нравственная оценка с позиций современности. Ключевые слова: Н.К. Михайловский, субъективный метод, методология социальных наук, методология истории, социальные рамки познания, аксиология.
\end{abstract}

DOI: $10.37313 / 2658-4816-2020-2-4-72-78$

Девятнадцатый век вошел в историю науки как период становления познавательного инструментария и научного дискурса гуманитарных и социальных наук. Именно в XIX веке история как сфера знания обрела статус науки; во второй половине столетия возникла новая наука об обществе - социология. Тем не менее дискуссионным оставался вопрос о месте этих наук в системе научного знания: в частности, о том, может ли изучение человеческого общества, его прошлого и настоящего основываться на столь же строгих научных принципах, быть столь же объективным и непредвзятым, как в естественных и точных науках. O значимости этой дискуссии свидетельствует то, что в нее были вовлечены не только профессиональные ученые, но также общественные деятели, писатели и публицисты.

Наиболее последовательная попытка перенести в сферу гуманитарных наук классическую парадигму познания, основанную на стремлении к строгому объективизму, была связана с позитивизмом. Вдохновляясь, по словам американского исследова-

Леонтьева Ольга Борисовна, доктор исторических наук, профессор кафедры российской истоpuu.E-mail:oleontieva@yandex.ru теля П. Новика, «благородной мечтой» об объективности гуманитарного знания ${ }^{1}$, теоретики позитивизма доказывали, что в исторической науке гарантией объективности исследователя должен служить критический анализ исторических источников, из которых «можно извлечь... частные исторические факты для исторического знания» ${ }^{2}$. Представлялось, что чем более научно-беспристрастным будет познание человеческого общества и тех законов, по которым оно развивается, тем больше шансов отыскать научно обоснованные пути к лучшему будущему.

Однако в последней трети XIX в. в российской мысли на базе позитивизма складывается особое направление, получившее название «субъективной школы в социологии» или «субъективно-этической школы»; обычно к нему причисляют крупнейших народнических мыслителей: П.Л. Лаврова, Н.К. Михайловского, С.Н. Южакова, B.M. Чернова и других ${ }^{3}$. Приверженцы этого направления не только считали субъективизм неизбежным и неустранимым свойством познания в гуманитарных и социальных науках, но и отстаивали мнение, что ученые вправе пользоваться особым 
«субъективным методом» - при условии критической рефлексии относительно его применения.

Репутация субъективного метода в отечественной историографии долгое время была незавидна. Термины «субъективизм», «субъективный» в научном лексиконе традиционно ассоциируются с глубоко личным, предвзятым и пристрастным отношением к чему-либо; поэтому наименование «субъективная школа», как правило, использовали противники этого направления (прежде всего марксисты), желавшие подчеркнуть его ненаучный характер. «Субъективный метод», как с грустью констатировали в начале XX века сами его приверженцы, представлялся критикам «чем-то вроде «савраса без узды, носящегося по полю мысли исключительно по велению собственных капризов»» 4 . Научный интерес к «субъективному методу» пробуждается с 1960-х гг.; отечественные историки изучали «теоретический субъективизм» как обоснование народнической идеологии 5 . На рубеже XXXXI вв. идеи «субъективной школы» стали рассматриваться в их методологическом аспекте, в контексте истории познавательных поворотов в гуманитарных науках ${ }^{6}$. Однако до настоящего времени не предпринималось попыток сравнить, как сторонникам субъективного метода виделись перспективы его применения в социологии и в исторической науке - хотя, как мы увидим далее, различия носили здесь принципиальный характер.

Что же такое субъективный метод и как его трактовали сами его создатели?

Понятие «субъективного метода» предложил в 1851 г. Огюст Конт, основоположник позитивизма как научно-теоретического направления и социологии как науки об обществе. Согласно его представлениям, если в естественных науках открытие законов совершается путем индукции - восхождения от частного к общему, то для открытия законов социологии требуется, напротив, метод дедукции: конкретному социологическому исследованию должны предше- ствовать некие предварительные посылки, общие представления о ходе развития человеческого общества. При выдвижении этих посылок-гипотез существенную роль должно играть воображение исследователя; такую программу исследования Конт и обозначил как «субъективный метод» ${ }^{7}$.

На русскую почву данное понятие перенес П.Л. Лавров, придав ему нравственно-этическую окраску. В статье «Задачи позитивизма и их решение» (1868 г.) Лавров предлагал применять «субъективный метод» при изучении действий человека, общественных форм, исторических событий - везде, где в исследовании неизбежны категории «желаемого, приятного, полезного, должного»; пользуясь данным методом, исследователь должен совершать «нравственный суд в приложении к личности, к обществу, к прошедшему и будущему в истории» 8 .

Ведущим теоретиком «субъективного метода» вслед за П.Л. Лавровым стал народнический мыслитель Н.К. Михайловский. Публицист и литературный критик, он был властителем дум своего времени: по степени влияния на умы читающих современников Михайловского часто сравнивали с его великим предшественником В.Г. Белинским. Спектр научных интересов Михайловского был очень широк: он прекрасно разбирался в проблемах социологии, первым из отечественных мыслителей стал разрабатывать проблематику социальной психологии (в цикле статей о сознательном и бессознательном подражании в человеческом обществе, более известном как цикл о «героях» и «толпе»), неоднократно затрагивал проблемы исторического знания и философии истории. Сам критик считал, что его статьи адресованы не узким специалистам, а «профанам» - любознательным дилетантам, способным оценить самые разные сферы знания с точки зрения общечеловеческой пользы9.

Главной целью своей литературной деятельности Михайловский считал поиск «системы Правды», которая смогла бы объ- 
единить «правду-истину» (объективно-научное знание) и «правду-справедливость» (нравственную оценку $)^{10}$. То и другое стремление были в высшей степени характерны для его эпохи: «век позитивизма» выдвигал требование объективно-научного познания в гуманитарных науках, а общественная атмосфера пореформенной эпохи формировала потребность в нравственной оценке прошлого и настоящего. Соответственно, субъективный метод Михайловского вырос из стремления примирить «противоречия между... потребностью знания и потребностью нравственного суда, задачами разума и задачами чувства» ${ }^{11}$.

Основы теоретико-методологического подхода Михайловского к изучению человеческого общества были сформулированы в первой же его программной статье - «Что такое прогресс?» (1869 г.). Прежде всего, Михайловский допускал возможность, что «объективная точка зрения, обязательная для естествоиспытателя, совершенно непригодна для социологии, объект которой человек - тождествен с субъектом» ${ }^{12}$; «претензия на объективность может здесь только повести к сбивчивости, именно потому, что полная объективность недостижима» ${ }^{13}$. Дело в том, что, изучая общество, любой ученый «всегда приступает к исследованию с предвзятым мнением», которое, как считал Михайловский, «обусловливается двумя элементами: во-первых, запасом предыдущего, бессознательно или сознательно приобретенного опыта, и, во-вторых, высотой нравственного опыта исследователя» ${ }^{14}$.

O первом элементе «предвзятого мнения» - предпосылочном знании, обусловленном предшествующим опытом исследователя, - Михайловский говорил впоследствии во многих своих трудах. Так, в статье «Философия истории Луи Блана» он писал, что любая научная теория рождается не только на основе фактических данных, но и «из комбинации разнородных, более ранних впечатлений, из бессознательно усвоенных понятий» - «духовной пищи, вспоившей и вскормившей гения, быть может, совсем помимо его сознания» ${ }^{15}$. При этом, по Михайловскому, для рождения теории требуется еще и «счастливая умственная и нравственная организация» ученого, в частности, развитое воображение: «Постройкою гипотез оно, так сказать, закидывает сети, в которые могут быть уловлены предметы ... соответствующие размерам и крепости сетей» ${ }^{16}$. Как и Конт, Михайловский считал творческое воображение необходимой составляющей научного поиска; но важно отметить, что в социальных науках, по его мнению, «роль воображения осложняется выработкою идеалов», а значит, нравственными аспектами ${ }^{17}$.

«Второй элемент предвзятого мнения»нравственный уровень исследователя - согласно Михайловскому, «дает себя особенно чувствовать в социологии»: поскольку «здесь мы имеем дело не только с необходимым, но и с желательным», то, «кроме истинности, достаточной для естествоиспытателя, предвзятое мнение социолога должно отразить в себе его идеал справедливости и нравственности» ${ }^{18}$. Именно поэтому, считал Михайловский, отказаться от «предвзятого мнения» в социологическом исследовании значило бы «отказаться от всего своего умственного и нравственного капитала», что было бы и невозможно, и невыгодно для целей научной работы ${ }^{19}$. Как настаивал Михайловский, исследователю, напротив, «должно только заботиться о том, чтобы предвзятое мнение получило характер рациональной теории... Незачем маскироваться объективностью, а должно выяснить без остатка свою личность, дать себе полный отчет в своих желаниях, побуждениях и целях» ${ }^{20}$. «Предвзятое мнение», развившееся в «рациональную теорию», - не что иное как идеал общественного устройства, который, по убеждению Михайловского, должен служить критерием оценки общественных явлений.

Михайловский связывал субъективный метод не только с «предвзятым мнением», но и со способностью исследователя к эмпатии, «сочувственному переживанию»: 
«Может быть, ...мыслящий субъект только в таком случае может дойти до истины, когда вполне сольется с мыслимым объектом и ни на минуту не разлучится с ним, т.е. войдет в его интересы, переживет его жизнь, перемыслит его мысль, перечувствует его чувство, перестрадает его страданиями, проплачет его слезами» ${ }^{21}$. В статье «Записки профана» Михайловский предложил следующее определение своего метода: «Субъективным методом называется такой способ удовлетворения познавательной потребности, когда наблюдатель ставит себя мысленно в положение наблюдаемого» ${ }^{22}$.

Однако, по мнению Михайловского, главные препятствия для «сочувственного переживания» создает социальное устройство общества. Трудно и не всегда возможно «проплакать слезами» другого человека, войти в его положение, поскольку между людьми существуют социальные границы - разделение на управляемых и управляющих, занятых физическим трудом и занятых трудом умственным. В своих литературно-критических статьях Михайловский неоднократно подчеркивал, что социальная принадлежность накладывает свой отпечаток на весь психологический строй личности, причем сословные различия сказываются сильнее, чем национальная общность: так, Лев Толстой и его ученики из яснополянской школы - крестьянские мальчишки - представляют собой совершенно разные типы человеческой личности. Поэтому познание в гуманитарных науках неизбежно приобретает социальную окраску: «Скажи мне, к какому общественному союзу ты принадлежишь, и я скажу тебе, как ты смотришь на вещи» ${ }^{23}$.

С точки зрения Михайловского, исследователь может перешагнуть социальные границы познания лишь в том случае, если достигнет высокого нравственного уровня: чем выше уровень нравственного развития, тем шире круг социальных групп, миросозерцание которых доступно «сочувственному переживанию» исследователя. Именно поэтому Михайловский считал «нравственный опыт», «нравственную организацию» исследователя важным условием познания в социальных науках: «Бэкон - предатель, взяточник, клеветник и вместе великий мыслитель о природе возможен, факт налицо. Но Бэкон - великий социолог немыслим» ${ }^{24}$.

Таким образом, для Михайловского устранение субъективности из научного исследования означало бы устранение самого человека с его багажом предшествующего знания, социальным опытом, моральной рефлексией. Социология виделась ему не просто наукой, нацеленной на постижение «правды-истины», но действенным инструментом диагностики общественных проблем и преобразования общества в соответствии с идеалами «правды-справедливости». Поэтому путь к познанию человеческого общества, с точки зрения мыслителя-народника, лежит не через объективность (с его точки зрения - мнимую, недостижимую беспристрастность), а через способность к эмпатии и нравственному росту.

В какой же мере, по мнению Михайловского, субъективный метод применим в историческом познании?

В одной из своих работ Михайловский противопоставлял друг другу два типа исторических исследований. «Историк первого типа даст нравственную оценку того или другого деятеля истории, единичного и коллективного ...даст политическую оценку известного правового или экономического учреждения»; иными словами, свою задачу такой историк видит в том, чтобы «дать современникам тот или другой практический урок». Напротив, «историк второго типа покажет, как данные обстоятельства выдвинули и должны были выдвинуть именно таких, а не иных деятелей, такую, а не иную литературу, такие, а не иные учреждения»; задача такого труда - «в событиях прошлого, в их последовательной связи» отыскать «то, что обыкновенно не совсем правильно называется законами истории» ${ }^{25}$. С точки зрения Михайловского, две эти задачи 
вступают в определенное противоречие друг с другом: можем ли мы претендовать на нравственную оценку явлений прошлого, осознавая при этом, что появление «таких, а не иных деятелей, таких, а не иных учреждений» было исторически обусловлено, а значит, закономерно? Как примирить в данном случае «потребность знания и потребность нравственного суда, задачи разума и задачи чувства»? Наконец, допустимо ли вообще применять к деятелям прошлого свои собственные нравственные мерки и идеалы, сформированные в совершенно иных исторических условиях?

Михайловский искал ответ на этот вопрос в своих работах «Вольтер-человек и Вольтер-мыслитель», «Граф Бисмарк», «Предисловие к книге об Иване Грозном», «Иван Грозный в русской литературе». С его точки зрения, чтобы дать нравственную оценку тому или иному историческому лицу, необходимо прежде всего «выяснить его идеалы и цели», затем определить, не находилась ли его жизнь и деятельность в противоречии с этими идеалами и в какой степени сознавала это противоречие совесть самого исторического деятеля: «Если самого Грозного посещали муки совести за совершенные им злодейства и безумства, то почему же историки-апологеты не прислушались к этому голосу совести их героя, почему они не верят в этом случае ему самому?» ${ }^{26}$. На следующем этапе исследования необходимо определить, удалось ли современникам героя в аналогичной ситуации сделать более достойный нравственный выбор: «Если мы видим, например, что рядом с интересующим нас историческим лицом жили и действовали носители более высоких идеалов... или выбиравшие лучшие, чем он, средства для достижения своих целей, то, значит, не общие обстоятельства времени и места держали его на низменном уровне; он был, значит, низмен и для своего времени» ${ }^{27}$. Сам Михайловский охотно пользовался этим приемом - сопоставления нравственного уровня современников, исповедовавших сходные идеалы, - в своих исторических очерках: так, «юркий и увертливый» Вольтер в работе Михайловского не выдержал сравнения с бескомпромиссным сельским кюре-атеистом Жаном Мелье, Иван Грозный - с Максимом Греком и московским митрополитом Филиппом Колычевым.

Как представляется, в данном случае Михайловскому удалось найти достаточно выверенный баланс между потребностью в нравственной оценке и учетом исторического контекста. По его убеждению, познание истории не должно быть этически нейтральным - ведь «профанов» привлекает к изучению истории именно потребность в сопереживании людям прошлого. Однако оценивать людей иного времени, по убеждению Михайловского, надо не с позиций сегодняшнего дня, как при проведении социологического исследования, а с учетом идеалов и исторических условий их собственного времени (впрочем, Михайловский оставлял за историком право ранжировать идеалы и средства людей прошлого как «более высокие» или «низменные»). Тем самым Михайловский делал шаг не только к исторической психологии, но и к исторической аксиологии - изучению ценностей людей прошлого, определявших мотивы их действий.

Таким образом, в трактовке Михайловского субъективный метод носил междисциплинарный характер: мыслитель считал его применимым в истории и социологии - тех науках, где субъект познания (человек) совпадает с объектом. Он выделял несколько аспектов этого метода: «предвзятое мнение» исследователя - предпосылочное знание, формирующееся на основе предшествующего опыта, социальной среды и «духовной пищи»; воображение, необходимое для построения гипотез; способность к сопереживанию; наконец, оценка явлений прошлого и настоящего с позиций нравственного идеала. Однако в сфере истории субъективизм народнического мыслителя носил менее радикальный характер, чем в социологии: Михайловский полагал, что нравственная оценка деятелей прошлого 
допустима только в историческом контексте, при условии сопоставления идеалов, целей и методов изучаемого персонажа и его современников.

В этой программе гуманитарного познания ярко выражены представления об активной роли субъекта познания, а также черты антропологического подхода к истории. Аксиологическая, ценностная сторона «субъективного метода» в истории делает его актуальным и в наши дни - в частности, для преодоления морального релятивизма в отношении к прошлому.

\section{ПРИМЕЧАНИЯ}

${ }^{1}$ Novick $P$. That noble dream: The «objectivity question» and the American historical profession. Cambridge: Cambridge Univ. press, 1988. XII, $648 \mathrm{p}$.

2 Ланглуа Ш.-В., Сеньобос Ш. Введение в изучение истории / Пер. с фр. А. Серебряковой; Гос. публ. ист. б-ка России. 2-е изд. / Под ред. и со вступ. ст. Ю.И. Семенова. М.: [б.и.], 2004. С.182.

${ }^{3}$ Голосенко И.А., Козловский В.В. История русской социологии XIX - XX вв. М.: Онега, 1995. С.79.

${ }^{4}$ Чернов В.М. Философские и социологические этюды. М.: Сотрудничество, 1907. С.151.

${ }_{5}^{5}$ Галактионов А.А., Никандров П.Ф. Идеологи русского народничества. Л.: Изд-во Ленингр. ун-та, 1966. 147 с.; Хорос В.Г. Народническая идеология и марксизм (конец ХІХ в.). М.: Наука, 1972. 175 с.; Виленская Э.С. Н.К. Михайловский и его идейная роль в народническом движении 70-х - начала 80-х годов XIX века. М.: Наука, 1979. 302 с.; Зверев В.В. Реформаторское народничество и проблема модернизации России. От сороковых к девяностым годам XIX века. М.: УНИКУМ-ЦЕНТР, 1997. 366 с.

${ }^{6}$ Дорошенко Н.М. Философия и методология истории в России (конец XIX - начало XX в.). СПб.: Изд-во С.-Петерб. ун-та, 1997. 180 с.; Леонтьева О.Б. «Субъективная школа» в русской мысли: Проблемы теории и методологии истории. Самара: Изд-во «Самарский универси- тет», 2004. 200 c.

${ }^{7}$ Конт О. Катехизис промышленников (третья тетрадь) или система позитивной политики. Т. 1, ч. 1 // Родоначальники позитивизма. Вып. 2-й. Сен-Симон, Ог. Конт. СПб.: Брокгауз и Ефрон, 1910. С. 150-152.

8 Лавров П.Л. Задачи позитивизма и их решение // Лавров П.Л. Философия и социология. Избр. произв. в 2 т. Т. 1. М.: Мысль, 1965. С. 609-613.

${ }^{9}$ Михайловский Н.К. Полн. собр. соч. 4-е изд. СПб.: Типогр. М.М. Стасюлевича, 1909. Т. 3. С. 277-280, 303-304, 332, 338, 423.

${ }^{10}$ Михайловский Н.К. Полн. собр. соч. 4-е изд. Т. 1. Стб. V; Т. 3. Стб. 386-388; Т. 4. Стб. 385-386, 405406.

${ }^{11}$ Михайловский Н.К. Полн. собр. соч. 4-е изд. Т. 6. Стб. 113.

${ }^{12}$ Михайловский Н.К. Полн. собр. соч. 5-е изд. СПб.: Типогр. М.М. Стасюлевича, 1911. Т. 1. Стб. 56.

${ }^{13}$ Михайловский Н.К. Полн. собр. соч. 5-е изд. Т. 1. Стб. 142.

${ }^{14}$ Там же. Стб.12-13.

${ }^{15}$ Михайловский Н.К. Полн. собр. соч. 4-е изд. Т. 3. Стб. 8.

16 Там же.

17 Там же.

${ }^{18}$ Михайловский Н.К. Полн. собр. соч. 5-е изд. Т. 1. Стб. 14.

${ }^{19}$ Там же. Стб. 15.

20 Там же. Стб. 142.

${ }^{21}$ Там же. Стб. 56.

${ }^{22}$ Михайловский Н.К. Полн. собр. соч. 4-е изд. Т. 3. Стб. 402.

${ }^{23}$ Михайловский Н.К. Полн. собр. соч. 4-е изд. Т. 4. Стб. 461.

${ }^{24}$ Михайловский Н.К. Полн. собр. соч. 5-е изд. Т. 1. Стб. 134.

${ }^{25}$ Михайловский Н.К. Полн. собр. соч. 4-е изд. Т. 3. Стб. 106.

${ }^{26}$ Михайловский Н.К. Полн. собр. соч. 4-е изд. Т. 6. Стб. 125, 220.

${ }^{27}$ Там же. Стб. 125-126. 


\title{
THE «SUBJECTIVE METHOD» BY N.K. MIKHAILOVSKY IN SOCIOLOGY AND HISTORY: BACKGROUND KNOWLEDGE, EMPATHY, AND MORAL ASSESSMENT
}

\author{
(C) 2020 O.B. Leontyeva
}

\section{Samara National Research University named after Academician S.P. Korolev}

The article contains an analysis of the theoretical and methodological approach to the study of human society, developed at the end of the $19^{\text {th }}$ century by N.K. Mikhailovsky, a leading theorist of Russian Populism (Narodnichestvo). The author compares the prospects for the application of the «subjective method» elaborated by Mikhailovsky in sociology and history, and distinguishes some components of the «subjective method»: «biased representation» (background knowledge), empathy for the object of research, reconstruction of the ideals and goals of people of the Past, and their moral assessment from the standpoint of the modernity. Keywords: N.K. Mikhailovsky, subjective method, methodology of social sciences, methodology of history, social frames of knowledge, axiology

DOI: $10.37313 / 2658-4816-2020-2-4-72-78$

Olga Leontyeva, Doctor of History, Professor, 